\title{
A Economia Política da Reforma \\ Macroeconômica no Brasil, 1995-2002*
}

\author{
David Samuels
}

\section{INTRODUÇÃO}

$\mathrm{O}$ ex-presidente Fernando Henrique Cardoso realizou muitas reformas, mas seu governo deixou de resolver importantes problemas. A política fiscal é um dos casos mais óbvios de sucesso de sua gestão: o Plano Real estancou a inflação, estabilizou a economia e deu condições ao governo federal de conter os gastos descontrolados dos Executivos estaduais e municipais, que tinham sido o principal fator de instabilidade macroeconômica. A receita fiscal cresceu mais rapidamente que o Produto Interno Bruto - PIB, ajudando o governo a gerar superávits orçamentários de cerca de 3\% do PIB desde 1999 - um feito extraordinário para qualquer país, especialmente para o Brasil, onde os governos têm pouca tradição de gastar com parcimônia.

\footnotetext{
* Uma outra versão deste artigo foi publicada no Journal of Latin American Studies. O texto foi também apresentado em seminário no David Rockefeller Center for Latin American Studies, Universidade de Harvard, outubro de 2002, e na reunião de 2003 da Latin American Studies Association, em Dallas. Agradeço os comentários dos participantes desses encontros e também os de Fernando Abrucio, Octavio Amorim Neto, Leslie Elliott Armijo e Philippe Faucher. [A tradução do original em inglês "The Political Economy of Macroeconomic Reform in Brazil, 1995-2002" é de Vera Pereira.]
}

DADOS - Revista de Ciências Sociais, Rio de Janeiro, Vol. 46, n-4, 2003, pp. 805 a 835. 
Mas a política fiscal também é um dos mais permanentes desafios do país. Apesar da bem-sucedida estabilização da economia, as políticas monetária, cambial e fiscal que o governo FHC escolheu seguir criaram novos obstáculos com os quais o presidente Lula já está se defrontando e que continuarão a se impor aos governos posteriores. Apesar de grandes vitórias, essas políticas transferiram os piores aspectos da crise fiscal brasileira do plano federal para o das subunidades federativas - o que possivelmente tornou o problema mais administrável e impediu seu recrudescimento, mas não o eliminou. Assim, enquanto um otimista poderia concluir que a economia brasileira adquiriu estabilidade e credibilidade porque o governo federal estabeleceu controles sobre a dívida e os gastos públicos dos estados e municípios, e centralizou as dívidas dos Executivos regionais, um pessimista talvez concluísse que se o governo Fernando Henrique Cardoso resolveu problemas de um lado, criou-os de outro, transferindo-os às futuras administrações. O pessimista poderia ainda acrescentar que, na realidade, as políticas públicas do governo FHC contribuíram para aumentar a crise fiscal brasileira. O Brasil não se livrou do que parece ser uma permanente "crise fiscal do Estado". Não a despeito, mas por causa dos esforços do governo FHC, a dívida interna brasileira cresceu bem mais rápido que o PIB em sua gestão, passando de $\mathrm{R} \$ 60,7$ bilhões, ou 28,1\% do PIB, em 1994, para R \$ 633,2 bilhões, ou 50\% do PIB, em 2001 (Brasil. Ministério da Fazenda, Secretaria do Tesouro Nacional, 2002a).

Os próprios êxitos do Plano Real explicam a rápida acumulação da dívida. O problema mais importante não é tanto o nível da dívida, mas sua estrutura. Em primeiro lugar, boa parte da dívida brasileira tem prazo relativamente curto, o que deixa o país em uma posição de grande vulnerabilidade em face de crises de liquidez que afetem a possibilidade de refinanciamento do governo. Em segundo lugar, grande parte da dívida é vinculada ao dólar, e por isso, quando o real é desvalorizado, a dívida aumenta proporcionalmente. Desde janeiro de 1999, quando o Brasil desistiu de tentar manter a paridade do real com o dólar, até junho de 2002, somente a desvalorização da moeda acrescentou $\mathrm{R} \$ 72,8$ bilhões à dívida do país. Em terceiro lugar, outra parcela considerável da dívida é vinculada à taxa básica de juros, atualmente de mais de $20 \%$ ao ano. Tanto a equipe econômica de Fernando Henrique quanto a de Lula mantiveram taxas elevadas de juros na intenção de controlar a inflação, evitar a desvalorização do real 
e atrair investimentos em dólar. No entanto, somente a manutenção de juros elevados acrescentou $\mathrm{R} \$ 109,4$ bilhões ao montante total da dívida (idem).

Em conseqüência disso, e apesar dos superávits primários que o país obteve desde 1999, a dívida pública não diminuiu. O governo brasileiro não pode fazer a economia crescer sem reduzir as taxas de juros e reformular o sistema tributário, mas não pode cortar os juros sem despertar temores inflacionários; além do mais, não há muita motivação para promover uma reforma tributária ampla que poderia trazer uma diminuição da receita governamental. Por outro lado, o governo não tem como prover as urgentes necessidades sociais sem aumentar suas despesas, e a exigência de fazer superávits orçamentários dificulta a transferência de recursos para programas sociais.

Os observadores do Brasil devem levar em conta os dois lados da questão ao avaliarem a gestão de Fernando Henrique Cardoso. Muitas vitórias foram obtidas, mas é necessário reconhecer seus ônus e compreender seu impacto sobre a gama de escolhas políticas disponíveis aos futuros governos. Este artigo pretende examinar os fatores que contribuíram para as dificuldades macroeconômicas enfrentadas pelo Brasil antes de 1995. Analiso, especialmente, como as instituições federativas, cuja importância cresceu com a redemocratização do país na década de 80 , limitaram a capacidade do governo federal de atingir uma situação de estabilidade econômica até meados dos anos 90. Analiso, depois, como o Plano Real possibilitou ao governo FHC restringir a capacidade dos Executivos subfederais de interferir na economia nacional. Em seguida, examino como os próprios êxitos do Plano Real ataram o país em uma "camisa-de-força fiscal" , e termino discutindo o que é necessário para que o Brasil se livre de tais limitações.

\section{O FEDERALISMO E AS LIMITAÇÕES DO GOVERNO FEDERAL: 1985-1994}

Durante a década de 80, o processo de democratização avançou no Brasil simultaneamente ao fortalecimento do federalismo (Souza, 1996; Abrucio e Samuels, 1997; Abrucio, 1998). No plano econômico, os anos 80 foram uma "década perdida" para o país devido ao lento crescimento do PIB e a uma inflação desenfreada. Sucessivos planos de estabilização fracassaram até que foi implantado o Plano Real. Não é possível compreender esses fracassos sem entender o impacto 
do federalismo na economia brasileira (Sola, 1993). Em conseqüência da redemocratização do Brasil, o federalismo deu aos atores políticos das subunidades federativas e aos seus representantes no Congresso Nacional o poder de determinar limites às iniciativas de reforma provenientes do Executivo, como também ocorreu na Argentina. Essas restrições compensavam os poderes presidenciais que a Constituição de 1988 havia consagrado. Explicarei de que modo o federalismo limitou as reformas examinando as conseqüências da descentralização fiscal e das dívidas dos governos dos estados e dos bancos estaduais.

\section{A Descentralização Fiscal}

O regime militar de 1964-85 centralizou a receita pública e por isso não surpreende que o processo de democratização no Brasil se tenha associado à descentralização fiscal. De 1965 a 1980, o governo federal aumentou sua parcela de alocação da receita fiscal de 54,8\% para $68,2 \%$, enquanto a parte correspondente aos estados diminuiu de $35,1 \%$ para $23,3 \%$ e a dos municípios de $10,1 \%$ para $8,6 \%$ (Varsano, 1996). Porém, à medida que a democratização avançava, os membros do Congresso procuraram desmontar as políticas do regime militar, de forma que, no período entre 1980 e 1995, a quota da receita abocanhada pela União voltou a representar $56,2 \%$ do total, enquanto a cota dos estados subiu para $27,5 \%$ e a dos municípios cresceu para $16,2 \%$ (Brasil. Ministério da Fazenda, Secretaria da Receita Federal, 2001b).

A descentralização fiscal interessava aos políticos recém-eleitos nos estados e municípios, mas contribuiu para piorar os déficits primários, que aumentaram sistematicamente em relação ao PIB durante toda a década de 80 e nunca atingiram o equilíbrio até a posse de Fernando Henrique na Presidência da República (World Bank, 2001). A razão disso é que as despesas do governo federal aumentaram mais rápido que as receitas, como proporção do PIB, nos anos 80 , visto que a nova Constituição, além de determinar a descentralização fiscal, dificultou as reformas da Previdência e da Administração Pública e obrigou a um aumento dos gastos em vários outros setores. Com a descentralização, diminuíram os recursos disponíveis pelo governo federal para fazer face às crescentes demandas do público em geral (Sola, 1993; Abrucio, 1998; Tavares de Almeida, 1995; Arretche, 2000). Os Executivos regionais continuaram a pressionar o governo federal por serviços e verbas, enquanto os presidentes se esforçavam para 
controlar as despesas públicas e transferir responsabilidades para as administrações dos estados e municípios.

O crescente desequilíbrio fiscal no plano federal reduziu a capacidade do governo de produzir estabilidade macroeconômica, fato que já era identificável no início da década de 90 (Bonfim e Shah, 1992; Werneck, 1992; Rezende, 1995). Entretanto, até 1994 nenhum presidente conseguira controlar os gastos ou o endividamento público. Sarney, Collor e Itamar Franco manifestaram por vezes a intenção de rever a descentralização fiscal, mas não lograram reverter o processo. O governo federal também cogitou de introduzir medidas destinadas a transferir responsabilidades do setor público para os estados e municípios, mas não as pôs em prática de forma séria. Resumindo: a descentralização fiscal criou obstáculos aos esforços do governo para equilibrar o orçamento, o que acabou contribuindo para as dificuldades macroeconômicas enfrentadas pelo Brasil no final dos anos 80 e começo dos 90 .

\section{As Dívidas dos Estados}

Apesar da descentralização fiscal, a situação financeira dos estados e municípios deteriorou-se ao longo da década de 80 e colaborou para a crise econômica brasileira. À medida que o processo de democratização tomava impulso, os novos governadores e prefeitos eleitos procuraram cumprir suas promessas de campanha e conquistar apoios aumentando as despesas de seus governos. Por exemplo, a folha de salários dos estados e municípios aumentou $77 \%$ em relação ao PIB no período de 1985 a 1990 (Werneck, 1992:10). Em 1997, os governos estaduais já acumulavam déficits da ordem de US\$139 bilhões. Limitações orçamentárias flexíveis estimularam esse comportamento, já que nenhum governador jamais teve de arcar com as conseqüências de realizar despesas deficitárias, pois o governo federal sempre assumia as dívidas dos estados quando recebia pedidos de socorro. Em 1989, o governo federal tomou a si a responsabilidade pelas dívidas dos estados com bancos estrangeiros, mas não conseguiu obrigar os Executivos estaduais a aceitar as condições que poderiam ter evitado mais uma crise da dívida; da mesma forma, em 1993 a União assumiu outros US $\$ 28$ bilhões de débitos estaduais. Os termos dos acordos entre estados e governo federal, por outro lado, geralmente incluíam condições generosas de pagamento, prazos extensos de amortização e taxas de juros abaixo das praticadas no mercado. Mesmo assim, os 
governos estaduais freqüentemente protelavam os pagamentos, obrigando a União a assumir, na prática, as dívidas deles (Abrucio e Ferreira Costa, 1998).

Os estados podiam transferir suas dívidas para a União porque a democratização havia atribuído considerável autonomia aos atores políticos regionais e também porque os presidentes brasileiros recorriam com freqüência à influência dos governadores para mobilizar apoio no Congresso aos projetos de interesse do Executivo (Abrucio, 1998). Além disso, enquanto a inflação persistiu, os déficits orçamentários gerados em qualquer nível de governo causaram, contraditoriamente, poucos problemas políticos imediatos, já que os governantes podiam reduzir o valor real das despesas postergando os desembolsos para salários e contratos durante um tempo suficiente para que a inflação produzisse seu efeito erosivo - o chamado "efeito Tanzi". Mas é claro que a expansão da dívida contribuiu para aumentar as pressões inflacionárias, criando-se portanto um círculo vicioso.

Embora os economistas advertissem que o descontrole dos gastos públicos estaduais contribuía decisivamente para as dificuldades do governo federal de estabilizar a economia no longo prazo (World Bank, 1990; Werneck, 1992; Novaes e Werlang, 1993; Dillinger, 1997), de Sarney a Itamar Franco nenhum presidente empenhou suficiente capital político para obrigar os governantes estaduais a conter seus gastos e pagar suas dívidas. Em vez disso, os presidentes quase sempre negociavam operações de salvamento das dívidas estaduais em troca do apoio dos governadores aos seus projetos no Legislativo. Em suma, a autonomia política dos estados, aliada a presidentes relativamente fracos, impôs obstáculos à solução dos problemas fiscais brasileiros e impediu o governo federal de promover a estabilidade macroeconômica.

\section{Os Bancos Estaduais}

Outro fator que muito contribuiu para a irresponsabilidade fiscal dos Executivos regionais foi o comportamento abusivo das instituições bancárias de propriedade dos estados. Desde 1993, 25 dos 27 estados brasileiros (inclusive o Distrito Federal) controlavam pelo menos uma instituição financeira (Novaes e Werlang, 1993:16). Esses bancos contribuíram para o desequilíbrio fiscal dos governos estaduais - e, por extensão, para o agravamento da situação econômica do país -, 
porque os governadores usavam politicamente "seus" bancos, tomando pesados empréstimos para cobrir despesas deficitárias. No entanto, dados seus horizontes políticos de curto prazo, eles geralmente se recusavam a pagar os empréstimos, com o que arruinavam a saúde financeira dos bancos estatais e contribuíam para a caótica situação fiscal do país. Entre 1982 e 1993, o Banco Central teve de intervir em 60 das 97 instituições financeiras estaduais, que estavam à beira da falência; em 1990, 45,3\% dos empréstimos dos bancos estaduais não estavam sendo pagos, em comparação com cerca de 1,7\% dos empréstimos de instituições privadas na mesma situação (Makler, 2000:46). Apesar de muitos observadores perceberem que a autonomia dos estados para usar e abusar de seus bancos prejudicava a implantação de medidas de estabilização econômica, até 1995 o governo federal sistematicamente socorreu bancos estaduais em troca de apoio político no Congresso.

\section{Resumo}

Uma característica das relações entre o governo federal e os Executivos estaduais no período de 1982 a 1994 foi um "federalismo predatório" (Abrucio, 1997). Estados e municípios se aproveitavam da dificuldade ou da relutância do governo federal em controlar as finanças dos Executivos subfederais. E os ônus desse federalismo predatório atingiram proporções alarmantes: os gastos públicos e a prática dos governos estaduais de transferir as dívidas decorrentes para a União contribuíram para a incapacidade de sucessivos presidentes de conter o déficit fiscal global do país e domar a inflação. Despesas deficitárias em todas as esferas de governo foram as principais causas da instabilidade macroeconômica anterior à introdução do Plano Real.

\section{ORIGENS E CONSEQÜENCIAS DO PLANO REAL}

Os políticos não deram ouvidos às advertências dos economistas até que Fernando Henrique Cardoso tomou posse como ministro da Fazenda em 1993. A equipe econômica nomeada pelo ministro foi a primeira a levar a sério a conexão entre inflação, estabilidade macroeconômica e desregramento fiscal (em todos os níveis de governo). O Plano Real, portanto, não teve como objetivo apenas o "controle" da inflação (como os planos anteriores, que efetivamente o conseguiram por um curto prazo), mas também introduzir o equilíbrio fiscal nas 
contas dos governos federal, estadual e municipal, e com isso manter um controle sustentável da inflação.

Para dominar a inflação no curto prazo, o real foi vinculado ao dólar americano, o que causou uma sobrevalorização da moeda brasileira e um aumento do valor das importações, gerando déficits em conta corrente. Para financiar esse déficit, manter o valor da moeda brasileira e sustentar um nível baixo de inflação, o governo também se empenhou em atrair investimentos em dólar. Para tanto, o Plano Real exigia taxas internas elevadas de juros. No entanto, o Brasil somente podia atrair investimentos estrangeiros, cumprir seus compromissos com o FMI e firmar uma credibilidade externa sustentável no longo prazo se também reduzisse a dívida pública. Em outras palavras, o Plano exigia austeridade fiscal em todas as esferas de governo (Souza, 1999:54).

Para gerar superávits nas contas do governo federal, a equipe econômica instituiu primeiramente o Fundo Social de Emergência - FSE, que desvinculou $20 \%$ de uma grande parcela da receita da União constitucionalmente reservada a determinadas despesas, com a finalidade de proporcionar ao governo federal maior liberdade de ação na aplicação dos recursos orçamentários. A instituição do FSE exigia uma emenda constitucional, porque a Constituição de 1988 vinculou a determinados fins boa parte da receita tributária. A aprovação de uma emenda constitucional exige, no Brasil, uma maioria de $60 \%$ dos membros das duas Casas do Congresso, o que levou Fernando Henrique Cardoso a mobilizar apoio parlamentar para esse aspecto essencial do Plano Real. Por essa época (outono de 1993), já tinham começado as campanhas para as eleições presidenciais de outubro de 1994. Como não haveria tempo de concluir a implantação do Plano Real antes de meados de 1995, o programa econômico foi inevitavelmente associado a um candidato comprometido em adotá-lo na futura administração.

Fernando Henrique Cardoso logo apareceu como óbvio candidato do "governo", de modo que a articulação de uma base de apoio parlamentar ao FSE e o respaldo à candidatura de FHC se tornaram inseparáveis. As dificuldades para fazer o Congresso a provar o FSE levaram Fernando Henrique, líder do PSDB, partido de centro-esquerda, a cortejar os principais políticos do PFL, partido de centro-direita. Aliados a Fernando Henrique e ao PSDB, os líderes do PFL perceberam 
que se o Plano Real conseguisse estabilizar a economia brasileira poderia trazer considerável apoio eleitoral para uma alternativa à candidatura oposicionista de Lula, do PT, que naquele momento liderava, por considerável margem, todas as pesquisas de intenção de voto (Dimenstein e Souza, 1994:130). O Congresso aprovou o FSE em fevereiro de 1994. Com a aproximação da data das eleições e a entrada em vigor do Plano Real, a inflação começou a despencar e o nome de Fernando Henrique logo subiu nas pesquisas. Ao fim e ao cabo, Fernando Henrique obteve uma vitória eleitoral irrefutável, já no primeiro turno.

O evidente sucesso do Plano Real não somente deu um impulso decisivo à eleição de Fernando Henrique Cardoso, como lhe rendeu notável apoio popular e parlamentar. E mais: ao contrário do que aconteceu com os outros presidentes após a redemocratização, o Plano Real deu a FHC poder e legitimidade suficientes para a construção de uma ampla e coesa coalizão governista, que comandava mais de $70 \%$ das cadeiras nas duas Casas do Legislativo, ao longo de seus dois mandatos - feito notável para qualquer presidente de uma nação. A legitimidade de Fernando Henrique e sua ampla coalizão de apoio lhe proporcionaram condições para levar a efeito importantes reformas destinadas a produzir estabilidade econômica no longo prazo e criar condições para o crescimento.

Examino, a seguir, como o Plano Real concedeu a Fernando Henrique uma vantagem estratégica sobre os Executivos regionais e potencializou as iniciativas de seu governo para alcançar o equilíbrio fiscal nas contas públicas.

O controle sobre os gastos dos estados e municípios foi uma decorrência das conseqüências políticas do Plano Real (Sola, Garman e Marques, 1997; Abrucio e Ferreira Costa, 1998). Domando a inflação, o Plano Real eliminou o "efeito Tanzi" e os governadores não puderam mais contar com a erosão inflacionária para reduzir suas contas; muitos se depararam com folhas de salário que comprometiam de $80 \%$ a $90 \%$ das receitas estaduais, tinham pouco dinheiro para pagar suas dívidas e menos recursos ainda para patrocinar os projetos clientelistas prediletos (Dillinger e Webb, 1999:23). O fato mais importante é que as altas taxas de juros fizeram subir vertiginosamente os juros cobrados sobre as dívidas dos estados, evidenciando a fragilidade da situação financeira dos governos estaduais (Afonso e Mello, 2000:16). 
Em resumo, os governos estaduais se viram, pela primeira vez depois da redemocratização, em uma situação fiscal insustentável, o que deu ao governo federal uma posição estratégica privilegiada para persuadir os governadores a mudarem de comportamento e aceitarem alterações nas regras. Fernando Henrique buscou então enrijecer as restrições aos gastos e ao endividamento dos estados e municípios e forçar a venda ou a reestruturação dos bancos estaduais (Garman et alii, 2000:40-61). Em outras palavras, o governo FHC utilizou os efeitos do Plano Real para impedir os governantes dos estados e municípios de interferirem no equilíbrio macroeconômico do país.

Seguindo a estratégia de análise usada nas seções anteriores, examino a seguir as conseqüências do Plano Real para o gasto público dos governos e dos bancos estaduais, e para a distribuição da receita entre as diferentes esferas governamentais no Brasil.

\section{As Despesas Estaduais}

Logo depois que o Plano Real entrou em vigor, em 1995, a situação financeira dos Executivos estaduais começou a deteriorar-se, tornando-os vulneráveis a pressões do governo federal. A equipe econômica de Fernando Henrique tirou partido dessa vantagem para renegociar as dívidas dos estados, arrancar de seus governantes compromissos concretos com o resgate de suas dívidas e impor novas restrições ao dispêndio e ao endividamento das futuras administrações. A “Lei Camata", por exemplo, aprovada em 1995, estipulou que a partir de janeiro de 1999 os estados deveriam limitar suas despesas totais com pessoal a $60 \%$ das receitas correntes líquidas, sob pena de retenção dos fundos federais. Quando o governo FHC aceitou refinanciar as dívidas dos estados, em 1997-98, exigiu que eles parassem de emitir títulos para cobrir suas dívidas até que o montante total dos débitos representasse menos de um ano da receita tributária. Em junho de 1998, o Conselho Monetário Nacional proibiu ainda os governos estaduais de contrair novos empréstimos no exterior.

As restrições impostas pela União funcionaram: quando o Estado de Minas Gerais suspendeu o pagamento de sua dívida, logo no início de 1999, Fernando Henrique bloqueou os repasses federais e confiscou recursos dos bancos estaduais para cobrir as parcelas não pagas, o que fortaleceu a credibilidade do governo federal. Em maio de 2000 foi aprovada a Lei de Responsabilidade Fiscal - LRF, que buscava aca- 
bar de uma vez por todas com a visão de que os governos estaduais e municipais gozam de "restrições orçamentárias flexíveis" (soft budget constraints). A LRF determinou limites rígidos de endividamento para todos os níveis de governo e proibiu expressamente a União de refinanciar futuras dívidas de Executivos subfederais. A Lei procurou ainda aumentar a "transparência da gestão fiscal" ao exigir que os governos estaduais e municipais publiquem uma prestação de contas de receitas e despesas, e estabelecer punições às autoridades públicas que violem a Lei ${ }^{1}$. A LRF foi uma das estratégias do governo Fernando Henrique Cardoso para controlar os gastos dos Executivos regionais: embora de 1994 a 1998 as administrações locais e estaduais tenham operado todos os anos com déficits primários, de 1999 em diante, de modo geral, elas acumularam superávits orçamentários ${ }^{2}$.

\section{Os Bancos Estaduais}

O governo Fernando Henrique Cardoso também estabeleceu um controle mais rigoroso sobre os bancos estaduais. Desde fins de 1994, quando interveio nos bancos dos estados do Rio de Janeiro e de São Paulo, o governo federal sinalizou que não iria mais salvar bancos falidos sem levar nada em troca. A pesar da rejeição do Congresso à proposta inicial do presidente para resolver a crise dos bancos estaduais, que obrigou o governo a pagar um preço muito maior por uma solução do problema, a administração de Fernando Henrique Cardoso conseguiu por fim intervir e organizar a privatização de quase todos esses bancos, impedindo com isso um possível reaparecimento do problema. Para compensar os governadores pela perda do controle sobre os bancos estaduais, a União refinanciou as dívidas dos estados com seus bancos, os quais também foram transferidos para o governo federal em condições favoráveis (Garman et alii, 2000). Em conseqüência dessas mudanças, os governos estaduais não podem mais usar as instituições bancárias estatais como fontes ilimitadas de empréstimos para cobrir gastos deficitários, e os bancos não podem mais enfraquecer o controle do Banco Central sobre a política monetária nacional.

\section{Uma Recentralização Fiscal?}

As políticas macroeconômicas instituídas pelo governo FHC não se limitaram a acabar com a hiperinflação e a conter as prodigalidades das administrações estaduais e municipais. O governo também se 
empenhou em gerar superávits orçamentários anuais, ainda que tivesse de enfrentar críticas por não gastar mais com programas sociais ou com o desenvolvimento da infra-estrutura do país. Para tanto, buscou principalmente aumentar a receita tributária ${ }^{3}$, no que foi bem-sucedido: invertendo a tendência predominante no período 1980-95, a receita da União cresceu no governo FHC, passando de $56,2 \%$ para 59,9\% da totalidade da receita governamental entre $1995 \mathrm{e}$ 2000 , enquanto a parcela dos estados caiu de $27,5 \%$ para $25,1 \%$ e a dos municípios, de 16,2\% para 15\% (Brasil. Ministério da Fazenda, Secretaria da Receita Federal, 2001b; 2001c). Esse fato levou alguns observadores a sugerir que a gestão de Fernando Henrique Cardoso inverteu o sentido da descentralização fiscal (Kugelmas, 2001). Contudo, esses dados dizem respeito apenas aos níveis relativos da receita, não aos níveis absolutos. Na verdade, em termos absolutos, a receita dos estados e municípios aumentou durante a década de 90, mas não tão rapidamente quanto a da União. Em todas as esferas de governo, a receita aumentou de 25,2\% do PIB em 1991 para 34,2\% em 2001 (uma alta até então inédita) (Lavoratti, 2002). Nesse período, a receita da União cresceu $37,4 \%$ em relação ao PIB, a dos estados, $19,2 \%$ e a dos municípios, 25,6\% (Brasil. Ministério da Fazenda, Secretaria da Receita Federal, 2001b).

Uma disposição constitucional explica a razão de a receita da União ter crescido mais rapidamente que a dos demais níveis de governo, dando a impressão de uma recentralização. A receita da União pode ser proveniente de "impostos", de "contribuições" ou de uma variedade de taxas e multas. Segundo a Constituição de 1988, se a receita tributária do governo federal aumentar, as transferências para as subunidades federativas também devem aumentar. Mas a União não tem de repartir com estados e municípios a receita proveniente de contribuições, ao contrário da receita tributária. A parcela relativa da receita da União aumentou porque o governo federal dispôs-se conscientemente a elevar muito mais a arrecadação de contribuições do que a dos impostos. As contribuições passaram de $27,2 \%$ da receita da União em 1990 a 46,7\% em 2001 (idem, 2001a). Isto é, o governo federal conseguiu elevar sua parcela relativa da receita - e cumprir suas metas de superávits anuais - devido, em grande parte, ao crescimento da arrecadação de "contribuições", e não por reduzir suas transferências para governos estaduais e municipais ou porque a receita destes tenha diminuído em termos absolutos. 
Resumindo: as conseqüências políticas das medidas econômicas adotadas por Fernando Henrique Cardoso permitiram-lhe recuperar o controle sobre as finanças dos estados e municípios e eliminar muitos incentivos políticos contraproducentes que eram estimulados pelas instituições federativas brasileiras (Abrucio e Ferreira Costa, 1998; Afonso e Mello, 2000; Montero, 2001). Ademais, o governo usou com astúcia os instrumentos de que dispunha para incrementar sua receita. Na verdade, essas mudanças não constituem uma recentralização política, mas a restauração de um Poder Executivo coeso na política brasileira, como contrapeso necessário às instituições federativas nacionais (Samuels e Mainwaring, 2004). Seja como for, essa combinação de medidas atacou as razões essenciais do caos econômico anterior e serviu de alicerce para a estabilidade macroeconômica durante a maior parte dos dois mandatos do presidente Fernando Henrique Cardoso.

\section{Os Custos do Plano Real}

A despeito de suas realizações, o governo de Fernando Henrique teve de pagar um preço para "limpar a área", um preço que as futuras administrações federais terão de continuar pagando. A próxima seção examina o "outro lado" do sucesso da gestão FHC, discute como suas políticas acabaram criando uma "camisa-de-força fiscal" para a economia brasileira e avalia as chances de futuros governos realizarem novas reformas políticas.

\section{TOMA-LÁ-DÁ-CÁ: NEGOCIANDO O FSE EM TROCA DAS DÍVIDAS DOS ESTADOS}

A gestão FHC conseguiu deter a interferência das administrações estaduais e municipais na estabilidade da economia nacional, mas para isso o governo federal teve de arcar com uma parte desproporcional dos custos. Em troca do apoio dos governadores ao FSE, que ajudou a aprová-lo no Congresso, o governo federal concordou em assumir as dívidas dos estados e refinanciar os débitos dos bancos estaduais numa escala ainda maior do que foi feito anteriormente. No início de 2002, a União já assumira $R$ \$297,7 bilhões de dívidas dos estados, representando aproximadamente 25\% do PIB nacional (Brasil. Ministério da Fazenda, Secretaria do Tesouro Nacional, 2002a). Embora os estados tivessem de comprometer parte das receitas para pagar suas dívidas, na realidade uma boa parte dos custos ficava com a União, que 
oferecia taxas de juros abaixo do mercado e prazos longos de amortização. O subsídio direto da União aos estados foi estimado entre US\$ 32 bilhões e US $\$ 46$ bilhões (em valores de 1977) (Rigolon e Giambiagi, 1998:15). Este subsídio reduziu o montante da dívida dos estados ao mesmo tempo que elevou a dívida da União, impondo restrições ao orçamento do governo federal por um futuro indeterminado.

\section{O Custo Total}

A tentativa de sanar as finanças dos estados foi somente um aspecto da política fiscal do governo Fernando Henrique Cardoso. De modo geral, as medidas então adotadas contribuíram para elevar a relação da dívida com o PIB brasileiro, de 28\% em 1994 para 56\% em 2001 (Brasil. Ministério da Fazenda, Secretaria do Tesouro Nacional, 2002a). O aumento total foi de $\mathrm{R} \$ 563,2$ bilhões. A Tabela 1 detalha as origens da dívida acumulada durante o governo FHC.

Mais da metade do aumento da dívida pública mobiliária do país proveio da reestruturação e refinanciamento das dívidas dos estados e municípios ${ }^{4}$. Algumas fontes não têm relação direta com o Plano Real ou com as negociações envolvidas em sua aprovação. Por exemplo, $\mathrm{R} \$ 128,2$ bilhões devem-se ao reconhecimento de dívidas acumuladas por bancos e órgãos federais não contabilizadas durante anos. Outros $\mathrm{R} \$ 45,2$ bilhões correspondem a subsídios e isenções fiscais concedidos pelo governo federal - por exemplo, através da Lei Kandir, que visa promover a competitividade das exportações brasileiras isentando-as do pagamento de ICMS estadual. Isso pode ser vantajoso para as exportações, mas o fato é que a Lei custou muito caro à União, porque os governos estaduais são reembolsados pela receita que deixam de arrecadar.

A Tabela 1 indica que o governo abateu $\mathrm{R} \$ 76,1$ bilhões da dívida com os superávits orçamentários anuais obtidos desde 1999, ao que se acrescentaram $\mathrm{R} \$ 58,9$ bilhões provenientes das privatizações ${ }^{5}$. Esses ganhos impediram um crescimento ainda maior da dívida pública, mas é preciso olhar esses valores com cautela: os "ganhos" não igualam os aumentos da dívida gerados pela política cambial e de juros do próprio governo, que foram responsáveis por um acréscimo de $\mathrm{R} \$$ 182,2 bilhões no endividamento total. 
Tabela 1

Crescimento da Dívida Mobiliária Federal no Brasil (1995-2002)

\begin{tabular}{l|c}
\hline Origem da Dívida ou Crédito & $\begin{array}{c}\text { Valor } \\
\text { (em bilhões de reais) }\end{array}$ \\
\hline Estoque da dívida em 1994 & 60,7 \\
Refinanciamento das dívidas dos estados e municípios e & 297,7 \\
$\quad$ dos bancos estaduais & \\
Títulos emitidos pelo Tesouro Nacional para facilitar a & 44,9 \\
$\quad$ rolagem & 72,8 \\
Impacto das flutuações do câmbio & 109,4 \\
Impacto das taxas de juros nominais & 128,2 \\
Reconhecimento de dívidas não contabilizadas (total) & 25,5 \\
$\quad$ Banco do Brasil & 39,8 \\
$\quad$ PROEF & 14,6 \\
$\quad$ SFH & 48,2 \\
Outros & 45,2 \\
Incentivos fiscais e subsídios (total) & 24,0 \\
$\quad$ Lei Kandir & 5,4 \\
Reforma agrária & 4,5 \\
Subsídios diretos às exportações & 11,3 \\
Outros & $\mathbf{5 8 , 9 )}$ \\
Privatizações (valor abatido da dívida) & $\mathbf{7 6 , 1 )}$ \\
\hline Total (em 31/12/2001) & $\mathbf{6 2 3 , 9}$ \\
\hline
\end{tabular}

Fonte: Brasil. Ministério da Fazenda, Secretaria do Tesouro Nacional (2002d).

O governo manteve um patamar elevado de taxa de juros para afastar o medo de uma volta da inflação e também para atrair investidores estrangeiros. Contudo, a taxa de juros determina o montante de juros sobre a dívida que o governo paga todos os anos (e certamente também interfere no conjunto da economia). Os pagamentos de juros aumentaram anualmente desde que o Plano Real entrou em vigor. $\mathrm{O}$ Brasil destina atualmente $8 \%$ do seu PIB ao pagamento de juros, quase três vezes mais que a média de outros países latino-americanos 
$(2,6 \%)$. Outros $20,5 \%$ de todas as despesas governamentais correspondem a pagamentos de juros, duas vezes a média do restante da América Latina (10,9\%) (International Monetary Fund, 2002). Quanto ao impacto das flutuações cambiais, a desvalorização do real elevou ainda mais a dívida na segunda gestão de Fernando Henrique Cardoso, depois que o governo resolveu abandonar a paridade com o dólar, em janeiro de 1999. A dívida brasileira aumenta quando o real perde valor em relação ao dólar, porque uma parte dela deve ser paga em dólares e não em reais.

Em muitos outros países a relação dívida/PIB é semelhante à do Brasil, só que aqui essa proporção é mais problemática, uma vez que $80 \%$ da dívida está vinculada ao valor do dólar ou à taxa interna básica de juros, e também porque os títulos públicos têm, em média, prazos de vencimento mais curtos. Esses fatores deixam o Brasil numa situação especialmente vulnerável aos acontecimentos internacionais e a possíveis problemas de financiamento de curto prazo (Batista, 2002). Dessa maneira, criou-se um círculo vicioso: para manter o real em níveis estáveis, conter a inflação e atrair investimentos em dólar, o governo precisa fixar taxas elevadas de juros; isso aumenta a dívida, o que, por sua vez, reduz a confiança no real e, em conseqüência, diminui a atratividade de investir dólares no Brasil. O resultado é uma pressão maior para a desvalorização do real, o que acaba fazendo crescer o nível da dívida.

Em suma, o crescimento da relação dívida/PIB no Brasil durante a gestão de Fernando Henrique Cardoso não foi uma conseqüência do desregramento dos gastos públicos, mas da própria política de juros e de câmbio do seu governo, e decorreu dos esforços para sanar as finanças da União e dos estados e municípios. Ao contrário do que se poderia esperar, embora a responsabilidade fiscal fosse um objetivo básico do Plano Real, as políticas do governo federal provocaram a explosão da dívida pública. E o que é mais grave, certos obstáculos políticos impediram o governo de obter mais vitórias na gestão da política fiscal, conforme examino nas próximas seções. Pressões provenientes principalmente dos governos dos estados e dos municípios limitaram o alcance da centralização da receita pública na gestão $\mathrm{FHC}$, e os próprios objetivos do governo federal impediram a tentativa de realizar uma ampla reforma fiscal que poderia estimular o crescimento econômico no longo prazo. 


\section{As Limitações da Reforma (1): Os Governos Estaduais e Municipais Não Podem Perder Receitas}

Apesar de o Plano Real estar centrado no aumento da capacidade do governo brasileiro para formular e levar a cabo seus objetivos, a gestão FHC não impôs de pronto o Plano Real ou algum de seus aspectos às demais unidades da Federação. A implantação do Plano Real envolveu extensas negociações entre governos, bem como entre o Executivo e o Legislativo. O governo federal realmente conseguiu seu importante objetivo de restringir a interferência dos Executivos subfederais na gestão macroeconômica do país, mas apesar de Fernando Henrique ter tido a intenção inicial de cortar as transferências fiscais para essas regiões, sua administração não conseguiu fazê-lo. Além de subsidiar as dívidas locais e estaduais para obter a aprovação do FSE, Fernando Henrique também teve de aceitar que os Executivos regionais não recebessem menos recursos na forma de repasses federais do que tinham recebido em 1993. Assim, embora o FSE "liberasse" até $20 \%$ da arrecadação da União das vinculações determinadas pela Constituição, o governo federal não cortou suas transferências na mesma proporção.

Em dezembro de 1993, o governo propôs que o FSE “desvinculasse" $15 \%$ de toda a receita da União, inclusive a receita a ser transferida para os estados e municípios conforme determina a Constituição. Governadores, prefeitos e até membros da coalizão parlamentar do presidente se opuseram à proposta, e partidos da base aliada do governo obstruíram uma votação do projeto em janeiro de 1994. Em razão disso, o governo propôs três medidas: (a) um aumento das alíquotas do imposto de renda; (b) que 5,6\% de toda a arrecadação do imposto de renda e $100 \%$ da receita proveniente do imposto de renda dos servidores públicos federais deixassem de ser incluídos no cálculo do montante a ser transferido para estados e municípios (sem o FSE, a Constituição determina que toda a arrecadação do imposto de renda seja consolidada e que as subunidades federativas recebam cerca de $45 \%$ do total); (c) como compensação pela não "liberação" pura e simples de $15 \%$ da arrecadação total do imposto de renda, o governo propôs que o FSE liberasse até $20 \%$ das demais receitas do governo. O Congresso aprovou a proposta um mês depois e promulgou o Fundo Social de Emergência (Motta, 1997; Landim, 1999). 
Entretanto, o projeto não reduziu em 5,6\% as transferências para estados e municípios - esse número corresponde à porcentagem estimada do aumento da receita do imposto de renda decorrente da elevação das alíquotas da tabela. Isto é, com o aumento da tabela, estados e municípios somente teriam de renunciar a 5,6\% de sua parcela futura do imposto de renda, mais a receita do imposto dos funcionários públicos federais. Mesmo com essas concessões, estados e municípios acabaram recebendo mais transferências da União depois da implantação do Plano Real. Já observei que a receita de impostos, em todas as esferas de governo, aumentou muito em relação ao PIB durante os dois mandatos de Fernando Henrique Cardoso, principalmente o imposto de renda das pessoas físicas, que passou de $2,61 \%$ para $4,01 \%$ do PIB entre 1994 e 2001 (Brasil. Ministério da Fazenda, Secretaria da Receita Federal, 2001a), devido ao aumento geral da tabela e à estratégia de permitir a mudança de uma faixa de renda ou de salário para uma alíquota mais alta por efeito da inflação, com o que mais brasileiros tiveram de pagar imposto de renda. A conseqüência de tudo isso é que as transferências constitucionais para estados e municípios aumentaram 124\% em valores reais entre 1994 e 2001. Nesse mesmo período, o PIB real cresceu apenas 18,2\% (Brasil. Ministério da Fazenda, Secretaria do Tesouro Nacional, 2002b; 2002c).

Apesar de todo o prestígio do presidente e da ampla coalizão que o apoiava, o governo federal não pôde simplesmente impor sua vontade na área tributária: teve de negociar o Plano Real com o Congresso e, em conseqüência, precisou ceder às pressões dos governadores e prefeitos, que defenderam ardorosamente no Legislativo os interesses fiscais de suas regiões. Por sua natureza especial, o FSE atribuiu aos legisladores uma considerável margem de manobra para defender seus interesses, revelando em que medida o êxito do Plano Real dependeu das negociações entre o Executivo e o Legislativo. O Plano Real distinguiu-se dos programas anteriores de reforma econômica no Brasil em dois aspectos essenciais: por descartar a estratégia de depender exclusivamente de decretos presidenciais e por adotar uma combinação de decretos e emendas constitucionais. Dessa forma, Fernando Henrique Cardoso comprometeu muito mais o Legislativo no processo de estabilização da economia. Obter apoio do Congresso a uma emenda constitucional é muito difícil no Brasil: os presidentes têm de negociar, fazer concessões e oferecer compensações pessoais para conseguir aprová-la. 
Contudo, a natureza peculiar da emenda constitucional que criou o FSE permitiu um comprometimento ainda maior do Legislativo. Quando se observa a aprovação de uma emenda constitucional em determinado país, geralmente pensamos que os políticos optaram por uma alteração permanente de um dispositivo político fundamental. Entretanto, a emenda constitucional que instituiu o FSE é de outra natureza: ela contém uma cláusula de vigência limitada, que já expirou e foi renovada por três vezes (em 1955, 1997, 1999), devendo expirar novamente em dezembro de 2003. Isso ajuda a explicar por que o Congresso aceitou de início o FSE: porque não era e não é uma reforma permanente das relações fiscais entre esferas de governo.

A cláusula de vigência limitada significa não só que os presidentes têm de negociar a aprovação original do Fundo a um custo substancial (os subsídios às dívidas e a garantia de manutenção dos níveis das transferências federais), mas também que deveriam voltar a negociar periodicamente a aprovação da mesma lei. Dessa forma, estados e municípios ganhavam novas oportunidades de obter vantagens adicionais em troca do apoio ao programa macroeconômico do governo, e, naturalmente, o presidente tem de fazer mais concessões do que se a emenda tivesse sido permanente desde o começo.

Toda vez que o prazo de vigência do FSE se aproximou do limite de expirar, Fernando Henrique teve de oferecer incentivos aos membros do Congresso para renovar a lei, e esses incentivos sempre incluíram fundos adicionais para os Executivos regionais. No ano 2000, por exemplo, todos os dispositivos do FSE que diziam respeito às transferências do imposto de renda para estados e municípios já tinham sido completamente removidos (Samuels, 2003:186-188).

Embora os futuros presidentes não tenham garantia alguma de que o Congresso irá prorrogar o Fundo indefinidamente, a dívida do país permanecerá até ser paga. O governo Fernando Henrique Cardoso jamais conseguiu realizar seus grandes objetivos - inverter de modo permanente a descentralização fiscal e desvincular permanentemente as receitas das transferências constitucionais para os estados e municípios. O Congresso sempre rejeitou essa mudança e se utilizou da cláusula de vigência limitada para arrancar concessões que pudessem beneficiar os estados e municípios. Tais concessões, junto com a assunção das dívidas dos estados, ilustram como os interesses dos Executivos subfederais condicionaram o espectro de opções do go- 
verno FHC, mesmo quando este mais reivindicava autonomia política. Os futuros governos provavelmente continuarão a depender do Congresso para manter programas de estabilização econômica.

\section{As Limitações da Reforma (2): O Fracasso da Reforma Tributária}

As medidas macroeconômicas do governo FHC não tiveram apenas um custo fiscal direto. A política fiscal do governo impediu, ademais, que se fizessem reformas mais amplas em outras áreas, especialmente no sistema tributário brasileiro ${ }^{6}$. Reforma tributária pode significar muitas coisas. No Brasil, os esforços concentraram-se no aperfeiçoamento da "qualidade" da tributação, na redução do chamado "custo Brasil", que torna os produtos brasileiros menos competitivos. Algumas metas específicas da reforma fiscal incluem a eliminação de impostos cumulativos, a ampliação da base tributária, a redução do número de impostos, a criação de incentivos para aumentar a receita, o fim dos incentivos (isenções fiscais) estaduais para atrair investimentos industriais e a mudança do modo de tributação da produção e do consumo ${ }^{7}$.

Desde antes da posse de Fernando Henrique Cardoso havia no Brasil um amplo e forte apoio à reforma fiscal. Os economistas concordavam que esta iria melhorar a eficiência e atrair investimentos. Ainda na função de ministro da Fazenda, Fernando Henrique dizia que o país necessitava urgentemente de uma reforma fiscal e durante sua campanha para presidente da República declarou que ela seria uma prioridade de seu governo; depois de empossado, repetiu inúmeras vezes essa declaração (Veja, 31/1/2001:42-43). Durante a década de 90, circularam no Congresso mais de sessenta projetos de reforma fiscal, sugerindo um grande interesse dos parlamentares nesse assunto (Azevedo e Melo, 1997:81). As principais associações empresariais do país também fizeram intenso lobby em favor da reforma tanto no Legislativo quanto no Executivo (Confederação Nacional da Indústria, 2000). O próprio Fernando Henrique enviou ao Congresso um projeto de reforma fiscal sete meses após sua posse (Proposta de Emenda Constitucional no 175). Entretanto, apesar da aparente convergência de pensamentos e interesses, e ao contrário de outros importantes projetos de reformas que lograram aprovação, a reforma fiscal ampla não prosperou durante os dois mandatos de Fernando Henrique Cardoso. Uma explicação dessa inércia está na relutância do governo em 
alterar um sistema que, apesar de oneroso e ineficiente, ajudou-o a realizar suas metas fiscais.

Toda reforma fiscal, especialmente num país com um sistema tão complexo como o do Brasil, implica um alto grau de incerteza sobre os fluxos futuros da receita (Ascher, 1989). Por esse motivo, muito embora a maioria dos atores seja, em princípio, favorável à reforma, também receia que os modelos de projeção dos economistas estejam errados e que eles venham a perder receita. Assim, apesar de afirmar repetidas vezes que a reforma fiscal era uma alta prioridade de seu governo, a principal prioridade de Fernando Henrique Cardoso foi sustentar o Plano Real, o que exigiu o conservadorismo fiscal: já que a receita vinha aumentando regularmente, o governo posicionou-se, por instinto, a favor da manutenção do status quo e jamais empenhou os recursos políticos necessários à aprovação de seu próprio projeto.

Acima de tudo, as normas constitucionais foram responsáveis pela estratégia de FHC de opor-se à reforma. Todos os projetos de reforma fiscal implicavam a redução ou extinção das chamadas "contribuições", devido a uma suposta ineficiência econômica ${ }^{8}$. No entanto, o governo precisa da receita das contribuições para gerar superávits orçamentários. Se as contribuições fossem transformadas em impostos, o governo teria de enfrentar um princípio fundamental do federalismo brasileiro estabelecido na Constituição de 1988: a partilha da receita tributária com os estados e municípios. Assim, as normas constitucionais que permitem ao governo arrecadar toda a receita das contribuições, mas o obrigam a dividir a receita proveniente de impostos, deixaram o governo FHC entre a cruz e a caldeirinha no tocante à reforma fiscal: se as contribuições prejudicavam o crescimento econômico no longo prazo, eram essenciais para a estabilidade da economia no curto prazo. O governo optou por evitar o que, de sua perspectiva, parecia ser a pior conseqüência do sistema de distribuição de receita do Brasil - a repartição da receita tributária -, e escolheu ficar com o que lhe parecia ser um sistema menos pior e lhe permitia não só cumprir suas obrigações internacionais como também sustentar seu programa macroeconômico. O desejo de evitar os efeitos das instituições de partilha da receita obrigou-o a essa escolha estratégica9 ${ }^{9}$.

O Brasil precisa superar a visão de que suas instituições estimulam a ineficiência econômica para poder gerar investimentos e aumentar a competitividade internacional dos seus produtos. A reforma fiscal te- 
ria ajudado nesse sentido. Entretanto, a despeito das repetidas declarações do presidente da República, da atuação de congressistas bem-intencionados e do pesado lobby empresarial, a reforma fiscal não avançou muito durante o governo de Fernando Henrique Cardoso. A rigor, a perspectiva de uma ampla reforma fiscal parecia menos provável ao final da gestão FHC do que no começo: a dependência crescente do governo federal em relação às "contribuições" levou-o a interessar-se menos pela reforma, e a eliminação de outros mecanismos de política industrial (por meio da privatização dos bancos estaduais e outros órgãos governamentais, bem como das limitações impostas aos níveis de endividamento dos estados) induziu os governadores a relutarem em abrir mão do poder de manipular impostos estaduais (ainda que o poder de conceder isenções tributárias como instrumento para atrair investimentos tenha custado aos estados uma perda de no mínimo US\$ 9 bilhões no início da década de 90) (Abrucio, 1998:233).

\section{Resumo}

A análise das negociações políticas realizadas para a aprovação e manutenção do Plano Real mostra que o governo Fernando Henrique Cardoso pagou um alto preço por seus êxitos, não fez tudo o que queria, e que suas escolhas políticas exacerbaram o problema fiscal brasileiro, assim como criaram obstáculos a reformas profundas em outras áreas. Em primeiro lugar, o governo concordou em subsidiar as dívidas dos estados e municípios porque não tinha outra saída para manter a credibilidade de todo seu esforço de estabilização da economia. Em segundo, embora tivessem realizado outros objetivos, as políticas de câmbio e de juros do governo também contribuíram para o crescimento da dívida, enfraquecendo, contraditoriamente, os princípios do Plano Real. Em terceiro, Fernando Henrique não pôde introduzir o Plano Real sem negociar seus pontos essenciais com o Congresso, onde os representantes dos governos locais e estaduais exigiam compensação por terem abdicado de elementos fundamentais da autonomia contraproducente que haviam conquistado durante a transição para a democracia. Em quarto lugar, o governo negociou o projeto original para o FSE de forma que os estados e municípios não perdessem receita (na realidade, eles acabaram ganhando). O caráter "temporário" dos principais pontos da política de estabilização implica que os futuros governos terão de ser tão habilidosos na negociação com o 
Congresso quanto Fernando Henrique se quiserem manter a estabilidade macroeconômica. Finalmente, a estratégia escolhida pelo governo impediu o avanço de reformas indispensáveis em outras áreas, especialmente a reforma tributária. Essas escolhas não implicam que o Brasil se encaminha para uma crise do tipo argentino, mas é preciso estar atento às suas conseqüências políticas e econômicas. O crescimento da dívida brasileira impõe ao governo federal um pesado ônus que vai restringir a gama de opções políticas de que poderão dispor os futuros governos para solucionar novos problemas.

\section{CONCLUSÃO}

O esforço do governo FHC em eliminar os problemas fiscais brasileiros foi bem-sucedido. O Plano Real encurralou a inflação e deu ao governo federal flexibilidade suficiente para gerar superávits orçamentários; além disso, as conseqüências econômicas do Plano puseram os Executivos regionais numa posição mais frágil, o que permitiu ao governo federal negociar controles fiscais mais estritos sobre as finanças dos estados e municípios. Os avanços mais significativos talvez tenham ocorrido na disciplina fiscal dos Executivos subfederais: o governo FHC conseguiu resolver muitos problemas originários do período 1985-1994. De modo especial, a Lei de Responsabilidade Fiscal instituiu uma série de mecanismos de controle da dívida e das finanças dos Executivos regionais e impôs sanções a futuros abusos.

O governo FHC também conseguiu aumentar de modo notável a capacidade do governo federal para gerar receita tributária, alcançando níveis de arrecadação recordes. Aumentos da base tributária, novos impostos, melhora da eficiência administrativa e crescimento econômico lento mas constante - tudo isso ajudou a incrementar a arrecadação da União. O governo empenhou-se ainda em tornar a dívida brasileira mais manejável, apesar de seu aumento. Sobretudo durante o segundo mandato de FHC, o Tesouro e o Banco Central esforçaram-se para alongar os prazos de resgate dos títulos da dívida brasileira, o que reduz a pressão diária sobre as contas do governo. Em 1994, o prazo médio de resgate dos títulos da dívida interna era de dois meses, mas no final de 2002 estimava-se que somente $27 \%$ de toda a dívida tinha prazos de resgate inferiores a doze meses (Nassif, 2002:67).

Entretanto, esse esforço também demonstrou a extensão dos problemas fiscais remanescentes. Embora a situação do Brasil ao final do se- 
gundo mandato de Fernando Henrique Cardoso não fosse tão difícil quanto a da Argentina antes do colapso de sua economia, em fins de 2001 (entre outros motivos, porque a moeda brasileira é flutuante, a dívida não é integralmente em dólares, e as receitas tributárias vêm crescendo e não caindo), o nível dos investimentos continuou baixo, porque os investidores temem que a dívida do país acabe se tornando inadministrável e que por isso um futuro governo seja obrigado a declarar uma moratória implícita ou explícita. Em outras palavras, o êxito do governo FHC em algumas frentes significou, necessariamente, a criação de problemas em outras frentes. Gostaria de refletir um pouco sobre os futuros problemas.

O Brasil assinou um acordo com o FMI em outubro de 1998 que tinha duas metas fiscais: um superávit primário superior a 3\% do PIB a partir de 1999 e uma redução da relação dívida/PIB de 50-53\% para $46,5 \%$ no final de 2001. O primeiro objetivo foi alcançado a um custo social elevadíssimo - esse dinheiro poderia ter sido gasto em educação, saúde, desenvolvimento da infra-estrutura ou outros programas sociais. A política fiscal do governo FHC também onerou os contribuintes e a indústria - uma carga tributária pesada não atrai investimentos e torna os produtos brasileiros menos competitivos no mercado internacional. Entretanto, os futuros governos terão de sustentar essa política apenas para manter a dívida estável (O Estado de S. Paulo, 10/6/2002, p. B4). Se não mantiverem superávits orçamentários, a dívida poderá expandir-se, tendo como resultado um aumento da pressão sobre o real e, conseqüentemente, uma elevação dos preços e das taxas de juros, o que acabaria perpetuando ou mesmo agravando o círculo vicioso da dívida.

É importante notar que a gestão FHC gerou superávits primários sem manter controle sobre as despesas anuais; isto é, o superávit baseou-se mais no crescimento da receita do que em cortes no orçamento. Esse fato sublinha a distância entre a retórica da "austeridade fiscal", da "responsabilidade fiscal", e a "realidade fiscal" na gestão orçamentária do governo. A dívida não só cresceu vertiginosamente como houve um aumento considerável do gasto governamental em todas as áreas: 6\% anuais em média, enquanto o PIB cresceu apenas 2,4\% ao ano. Os gastos públicos não financeiros do governo passaram de 16,5\% do PIB em 1994 para uma estimativa de 21,8\% em 2002 (O Estado de S. Paulo, 14/4/2002, p. A4). E mais: as despesas com amortização da dívida e pagamento de juros aumentaram de modo ainda mais 
acelerado, e em todas as áreas os gastos com pessoal e com investimentos cresceram bem mais rápido que o PIB (Nassif, 2002:67).

O governo não tinha como controlar seu gasto. O FSE ajudou a manipular a distribuição relativa da receita dentro do orçamento, mas não podia ajudar o governo a reduzir o nível absoluto do gasto público. Há dúvidas sobre se uma futura administração será realmente capaz de cortar gastos de modo substancial, principalmente porque apenas uma pequena parcela do orçamento pode ser cortada a cada ano. Em 2001, aproximadamente $75 \%$ do orçamento anual foi gasto com salários, aposentadorias e transferências diretas para indivíduos, rubricas em que não cabe veto presidencial (O Estado de S. Paulo, $10 / 6 / 2002$, p. B4). O total dessas despesas vinculadas chegou a quase $51 \%$ do orçamento em 1987 (Nassif, 2002:47). O crescimento da receita vinculada foi uma conseqüência, entre outras coisas, da expansão da burocracia (especialmente na década de 80) e dos aumentos dos salários dos servidores públicos (de 1995 a 2001 os gastos com pessoal no Executivo subiram 80,9\%) (O Estado de S. Paulo, 18/5/2002, p. A2). Dos 25\% restantes do orçamento, a Constituição vincula $40 \%$ (isto é, $10 \%$ do orçamento global) à saúde. Portanto, o presidente não pode recorrer aos seus poderes constitucionais para obter superávits fiscais. Os cortes de gastos terão de ser realizados mediante reformas sistemáticas que o governo FHC não fez ou que foram deturpadas quando tentou fazê-las, como a reforma administrativa e a reforma da previdência do setor público (Melo, 2001). Pode-se prever que as questões fiscais ainda ocuparão uma posição de destaque na agenda política de futuros governos.

A gestão macroeconômica, baseada no Plano Real, foi o maior êxito do governo de Fernando Henrique Cardoso. Contudo, o sucesso não foi completo. Os ganhos obtidos pelo governo federal custaram muito caro, principalmente pelo incremento dos encargos de uma dívida que ainda imporá por muito tempo restrições ao manejo flexível do orçamento público e às opções de política dos futuros presidentes. As próprias políticas de câmbio e de juros adotadas pelo governo FHC limitaram essa flexibilidade em outras áreas e deixaram o Brasil mais vulnerável às oscilações financeiras internacionais. Por fim, elementos fundamentais das políticas macroeconômicas continuam a depender de negociações pacíficas entre Executivo e Legislativo. Os desafios à estabilidade macroeconômica do Brasil continuam a localizar-se na área da política fiscal. As medidas tomadas pelo governo de 


\section{David Samuels}

\section{Fernando Henrique Cardoso consolidaram os problemas no plano fe- deral, revelando toda a extensão das perdas, mas não livraram o país do dano causado por governos anteriores.}

(Versão definitiva em outubro de 2003)

\section{NOTAS}

1. Apesar de restringir a autonomia das subunidades federativas, os governadores foram favoráveis à Lei de Responsabilidade Fiscal. O fato de esta ter levado apenas um ano para ser aprovada no Congresso é um indicador da pequena oposição ao projeto. Os governadores não se opuseram à LRF pois o governo federal já tinha resolvido seus problemas fiscais em 1999, e porque a lei deixa claras as condições em que eles podem demitir funcionários ou reduzir os salários dos servidores estaduais. Após a adoção do Plano Real e o controle da inflação, os governadores já não tinham motivos para usar o governo estadual como programa de emprego e passaram a relutar mais na concessão de aumentos salariais, porque podiam ficar sem recursos para investir em obras públicas. Mais informações sobre a LRF encontram-se em Mendes (1999), Afonso e Mello (2000), Cavalcanti e Quadros (2000), Kopits, Jiménez e Manoel (2000).

2. O crescimento da receita tributária nos estados e municípios ajudou (além do aumento das transferências do governo federal), principalmente o da receita do ICMS. Detalhes em Nassif (2002: 45-46).

3. O governo também estimulou os Executivos regionais a aumentarem a eficiência de seus sistemas tributários e a buscarem elevar suas receitas, em vez de ficarem na dependência exclusiva das transferências federais.

4. O momento em que se deu a solução da crise da dívida dos estados foi decisivo: o custo para o governo federal aumentou muito porque a operação somente foi concluída depois que a política de juros altos do próprio governo já inflacionara enormemente o valor das dívidas dos estados. Isso poderia ter sido evitado, mas com certeza elevou sobremaneira o ônus do governo federal.

5. As privatizações também ajudaram a reduzir as pressões sobre os orçamentos estaduais (e a eleger vários governadores em 1998): os estados ficaram com cerca de US \$34,7 bilhões provenientes das privatizações entre 1996 e 2001 (Nassif, 2002: 51). No entanto, assim como no plano federal, restaram poucas empresas e órgãos de relevo para vender.

6. A extensão da reforma administrativa também foi limitada pelas políticas fiscais do governo (Bressan, 2002).

7. Um detalhamento das propostas de reforma tributária e fiscal encontra-se, entre outros, em Afonso et alii (1998) e Lima (1999). 
8. O FMI, por exemplo, acha que a Contribuição Provisória sobre Movimentação Financeira - CPMF é uma das formas menos eficientes de tributação em todo o mundo. Cf. "Fundo Vê Riscos na Manutenção do CPMF", O Estado de S. Paulo, $18 / 6 / 2001$, p. B4.

9. Setores empresariais dos estados e municípios também foram veementemente contrários à reforma fiscal, e sua influência contribuiu para o fracasso das propostas de ampla reforma. Veja em Samuels (2003, cap. 9).

\section{REFERÊNCIAS BIBLIOGRÁFICAS}

ABRUCIO, Fernando Luiz. (1997), Jogos Federativos: O Modelo Predatório Brasileiro. CEDEC, São Paulo. Manuscrito.

. (1998), Os Barões da Federação: O Poder dos Governadores no Brasil Pós-Autoritário. São Paulo, EDUSP.

_ e FERREIRA COSTA, Valeriano Mendes. (1998), Reforma do Estado e Contexto Federativo Brasileiro. São Paulo, Konrad-Adenauer Stiftung.

ABRUCIO, Fernando Luiz e SAMUELS, David. (1997), “A 'Nova' Política dos Governadores: Política Subnacional e Transição Democrática no Brasil”. Lua Nova, no 40/41, pp. 137-166.

AFONSO, José Roberto R. e MELLO, Luiz de. (2000), Brazil: An Evolving Federation. Trabalho apresentado no IMF/FAD Seminar on Decentralization. Washington, DC.

AFONSO, José Roberto R., REZENDE, Fernando e VARSANO, Ricardo. (1998), “Reforma Tributária no Plano Constitucional: Uma Proposta para o Debate". Textos para

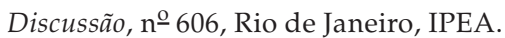

ARRETCHE, Marta. (2000), Estado Federativo e Políticas Sociais: Determinantes da Descentralização. São Paulo, FAPESP.

ASCHER, William. (1989), "Risk, Politics, and Tax Reform", in M. Gillis (ed.), Tax Reform in Developing Countries. Durham, Duke University Press.

AZEVEDO, Sérgio de e MELO, Marcus A. (1997), “A Política da Reforma Tributária: Federalismo e Mudança Constitucional". Revista Brasileira de Ciências Sociais, vol. 12, no 25 , pp. 75-100.

BATISTA, Paulo Nogueira. (2002), “O Efeito FHC”. Folha de S. Paulo, 27/5/2003, p. B2.

BONFIM, Antulio e SHAH, Anwar. (1992), "Macroeconomic Management and the Division of Powers in Brazil: Perspectives for the Nineties". Policy Research and External Affairs Working Paper, Washington, DC, The World Bank. 


\section{David Samuels}

BRASIL. Ministério da Fazenda, Secretaria da Receita Federal. (2001a), “Arrecadação das Receitas Administradas pela SRF e Participação Percentual no PIB (A Preços Correntes) - 1994 a 2001". Disponível em <www.receita.fazenda.gov.br>. Acessado em junho de 2001.

. (2001b), “Carga Tributária do Brasil - 2000 (tabelas)”. Disponível em <www.receita.fazenda.gov.br>. Acessado em junho de 2001.

. (2001c), “Carga Tributária do Brasil - 2000 (texto)". Disponível em <www.receita.fazenda.gov.br>. Acessado em junho de 2001.

BRASIL. Ministério da Fazenda, Secretaria do Tesouro Nacional. (2002a), “Dívida Pública: Conceitos Básicos e Fatores Determinantes". Disponível em <www.tesouro.fazenda.gov.br>. Acessado em junho de 2002.

_. (2002b), "Fundo de Participação dos Estados 1991-2001". Disponível em $<$ www.tesouro.fazenda.gov.br>. Acessado em junho de 2002.

. (2002c), “Fundo de Participação dos Municípios 1991-2001". Disponível em $<$ www.tesouro.fazenda.gov.br>. Acessado em junho de 2002.

. (2002d), "Dívida Pública: Conceitos Básicos e Fatores Determinantes". Disponível em <www.tesouro.fazenda.gov.br>. Acessado em junho de 2002.

BRESSAN, Sílvio. (2002), "Reforma Administrativa”, in B. Lamounier e R. Figueiredo (eds.), A Era FHC: Um Balanço. São Paulo, Editora Cultura.

CAVALCANTI, Carlos E. G. e QUADROS, Waldemir Luiz de. (2000), “Economia do Setor Público". Indicadores DIESP, vol. 77, pp. 28-31.

CONFEDERAÇÃO NACIONAL DA INDÚSTRIA. (2000), Agenda Legislativa da Indústria. Brasília, CNI.

DILLINGER, William. (1997), “Brazil's State Debt Crisis: Lessons Learned". World Bank Departmental Working Paper, no 17.430 . Washington, DC, The World Bank.

_ e WEBB, Steven B. (1999), “Fiscal Management in Federal Democracies: Argentina and Brazil". Policy Research Working Paper, n⿳⺈ 2.121. Washington, DC, The World Bank.

DIMENSTEIN, Gilberto e SOUZA, Josias de. (1994), A História Real: Trama de uma Sucessão. São Paulo, Editora Ática.

GARMAN, Christopher, LEITE, Christiane Kerches da Silva e MARQUES, Moisés. (2000), “Impactos das Relações Banco Central versus Bancos Estaduais no Arranjo Federativo pós-1994: Análise à Luz do Caso Banespa". Revista de Economia Política, vol. $21, \mathrm{n}$ 을 1 pp. $40-61$.

INTERNATIONAL MONETARY FUND. (2002), “World Economic Outlook" (April). Disponível em <www.imf.org $>$. Acessado em junho de 2002.

KOPITS, George, JIMÉNEZ, Juan Pablo e MANOEL, Álvaro. (2000), Responsabilidad Fiscal a Nivel Subnacional: Argentina y Brasil. Trabalho apresentado no XII Seminário Regional de Política Fiscal, CEPAL, Santiago de Chile, 24-26 de janeiro. 
KUGELMAS, Eduardo. (2001), "A Evolução Recente do Regime Federativo no Brasil", in W. Hofmeister e J. M. B. Carneiro (eds.), Federalismo na Alemanha e no Brasil. São Paulo, Konrad-Adenauer Stiftung.

LANDIM, Pinheiro. (1999), Relatório: Proposta de Emenda à Constituição no $85-\mathrm{A}$, de 1999. Brasília, Câmara dos Deputados, Comissão Especial Destinada a Proferir Parecer à PEC no 85-A/1999.

LAVORATTI, Liliana. (2002), "Arrecadação do ICMS Bate Recorde Histórico". O Estado de S. Paulo, 5/2/2002, p. B8.

LIMA, Edilberto Carlos Pontes. (1999), "Reforma Tributária no Brasil: Entre o Ideal e o Possível". Textos para Discussão, no 666, Rio de Janeiro, IPEA.

MAKLER, Harry. (2000), "Bank Transformation and Privatization in Brazil: Financial Federalism and Some Lessons about Bank Privatization". The Quarterly Review of Economics and Finance, vol. 40.

MELO, Marcus. (2001), O Jogo das Regras: As Reformas Constitucionais no Brasil: Instituições Políticas e Processo Decisório. Rio de Janeiro, Editora Revan.

MENDES, Marcos. (1999), Lei de Responsabilidade Fiscal: Análise e Alternativas. Instituto Fernand Braudel de Economia Mundial, São Paulo. Manuscrito.

MONTERO, Alfred. (2001), Competitive Federalism and Distributive Conflict in Democratic Brazil. Trabalho apresentado na Bildner Center Conference on Brazil. Columbia University.

MOTTA, João Ricardo. (1997), “A Prorrogação do FEF”. Correio Braziliense, 25/11/1997, p. 3.

NASSIF, Luis. (2002), "Política Macroeconômica e Ajuste Fiscal”, in B. Lamounier e R. Figueiredo (eds.), A Era FHC: Um Balanço. São Paulo, Editora Cultura.

NOVAES, Walter e WERLANG, Sérgio R. da Costa. (1993), "Financial Integration and Public Financial Institutions". Working Paper, no 225, Escola de Pós-Graduação em Economia da Fundação Getulio Vargas.

REZENDE, Fernando. (1995), “Federalismo Fiscal no Brasil”. Revista de Economia Política, vol. $15, \mathrm{n}-3$, pp. 5-17.

RIGOLON, Francisco e GIAMBIAGI, Fábio. (1998), Renegociação das Dívidas Estaduais: Um Novo Regime Fiscal ou a Repetição de uma Antiga História? BNDES. Manuscrito.

SAMUELS, David. (2003), Ambition, Federalism, and Legislative Politics in Brazil. New York, Cambridge University Press.

_ e MAINWARING, Scott. (2004), "Strong Federalism, Constraints on the Central Government, and Economic Reform in Brazil”, in E. Gibson (ed.), Representing Regions: Federalism and Territorial Politics in Latin America. Baltimore, The Johns Hopkins University Press.

SOLA, Lourdes. (1993), “Estado, Transformação Econômica e Democratização no Brasil", in L. Sola (ed.), Estado, Mercado e Democracia. São Paulo, Paz e Terra, pp. 235-279. 


\section{David Samuels}

_ , GARMAN, Christopher e MARQUES, Moisés. (1997), Central Banking, Democratic Governance and Political Authority: The Case of Brazil in a Regional Perspective. Trabalho apresentado no VXII Congresso da International Political Science Association, Seul.

SOUZA, Amaury de. (1999), "Cardoso and the Struggle for Reform in Brazil". Journal of Democracy, vol. 10, n으.

SOUZA, Celina. (1996), "Redemocratization and Decentralization in Brazil: The Strength of the Member States". Development and Change, vol. 27, pp. 529-555.

TAVARES DE ALMEIDA, Maria Hermínia. (1995), "Federalismo e Políticas Sociais". Revista Brasileira de Ciências Sociais, vol. 10, no28, pp. 88-108.

VARSANO, Ricardo. (1996), "A Evolução do Sistema Tributário Brasileiro ao Longo do Século: Anotações e Reflexões para Futuras Reformas". Textos para Discussão, no 405, Rio de Janeiro, IPEA.

WERNECK, Rogério. (1992), "Fiscal Federalism and Stabilization Policy in Brazil". Texto para Discussão, n- 282, Departamento de Economia/PUC-Rio.

WORLD BANK. (1990), The Dilemma of Brazil's State Banking System: An Analysis and Suggestions for Reform. Report no 8247-BR, Washington, DC World Bank, Country Operations Division, Brazil Department, Latin America and the Caribbean Region.

. (2001), World Development Indicators (CD-ROM). Washington, DC, The World Bank. 


\section{ABSTRACT}

The Economic Policy of Macroeconomic Reform in Brazil, 1995-2002

This article examines the successes and limits of the macroeconomic and fiscal reforms under the Fernando Henrique Cardoso Administration in Brazil. The author begins by studying factors that contributed to macroeconomic difficulties prior to 1995, then proceeds to examine how the Real Plan enabled the Cardoso Administration to control interference by State Governors in the national economy. The article then describes how former President Cardoso's policies generated the current "fiscal straitjacket" in Brazil, and concludes by discussing how the Cardoso government's legacy may continue to constrain action by future Brazilian Administrations.

Key words: Cardoso administration; Real Plan; macroeconomic reform; Brazil

\section{RÉSUMÉ}

L'Économie Politique de la Réforme Macroéconomique au Brésil, 1995-2002

Dans cet article, on examine les succès et les limites des réformes macroéconomiques et fiscales du gouvernement sous la présidence de Fernando Henrique Cardoso. On analyse d'abord les facteurs responsables des difficultés macroéconomiques avant 1995, ainsi que la façon dont le Plan Real a permis au gouvernement FHC de contrôler l'ingérence des exécutifs régionaux dans l'économie nationale. Ensuite on voit comment les politiques de président ont créé le "carcan fiscal" où se trouve actuellement le Brésil et montre que la gestion écoulée pourra restreindre l'action des gouvernements brésiliens à venir.

Mots-clé: gouvernement FHC; Plan Real; réforme macroéconomique; Brésil 